\title{
Synergistic immunotherapeutic effects of Lycium barbarum polysaccharide and interferon- $\alpha 2 b$ on the murine Renca renal cell carcinoma cell line in vitro and in vivo
}

\author{
SHIYOU CHEN ${ }^{1}$, LUNAN LIANG $^{2}$, YING WANG $^{3}$, JIANHUN DIAO $^{1}$, CHUNXIONG ZHAO $^{1}$, \\ GANG CHEN $^{1}$, YUNFENG HE ${ }^{1}$, CHUNLI LUO ${ }^{4}$, XIAOHOU WU ${ }^{1}$ and YAO ZHANG ${ }^{1}$ \\ ${ }^{1}$ Department of Urology, The First Affiliated Hospital of Chongqing Medical University, Chongqing 400016; \\ ${ }^{2}$ Department of Reproductive Medicine, The Affiliated Hospital of Jining Medical College, Jining, Shandong 272000; \\ ${ }^{3}$ Department of Oncology, The First People's Hospital of Jiulongpo District, Chongqing 400050; ${ }^{4}$ Department of \\ Laboratory Medicine, Chongqing Medical University, Chongqing 400016, P.R. China
}

Received October 31, 2014; Accepted July 28, 2015

DOI: $10.3892 / \mathrm{mmr} .2015 .4230$

\begin{abstract}
Novel therapeutic strategies to improve clinical efficacy in patients with renal cell carcinoma (RCC) are required. The possibility of combination therapy with Lycium barbarum polysaccharides (LBP) and recombinant interferon (IFN)- $\alpha 2 b$ remains to be elucidated in RCC. The present study investigated the putative synergistic immunotherapeutic roles of LBP and IFN- $\alpha 2 \mathrm{~b}$ against $\mathrm{RCC}$ in vitro and in vivo. The mouse RCC cell line, Renca, was used for in vitro experiments. Treatment of the cells with a combination of LBP and IFN- $\alpha 2 b$ markedly inhibited cell proliferation, retarded cell cycle growth and promoted apoptosis in the Renca cells. Western blot analysis revealed that LBP and IFN- $\alpha 2 b$ synergistically downregulated the expression levels of cyclin D1, c-Myc and Bcl-2, and upregulated the expression of the antiapoptotic protein, Bax. Myeloid-derived suppressor cells (MDSCs) were markedly upregulated during tumour progression and promoted tumour growth by inhibiting the T-cell-mediated immune response. In vivo, a marked reduction in the MDSC ratio and tumour volume was observed in a group receiving combined treatment with LBP and IFN- $\alpha 2 b$ in a xenograft tumour model. In conclusion, the present study suggested that the combination of LBP and IFN- $\alpha 2 b$ is likely to be more effective in treating murine RCC compared with the less pronounced immunotherapeutic effects of administering LBP or IFN- $\alpha 2 b$ alone.
\end{abstract}

Correspondence to: Professor Xiaohou $\mathrm{Wu}$ or Professor Yao Zhang, Department of Urology, The First Affiliated Hospital of Chongqing Medical University, 1 You Yi Road, Central District, Chongqing 400016, P.R. China

E-mail:wxiaohou2014@163.com

E-mail: zhangyao1030@126.com

Key words: Lycium barbarum polysaccharide, recombinant interferon- $\alpha 2 b$, immunotherapy, murine renal cell carcinoma, renca cells

\section{Introduction}

Renal cell carcinoma (RCC), which accounts for $\sim 3 \%$ of all malignancies, is one of the most lethal urologic malignancies (1) and 20-30\% of all patients are diagnosed with metastatic disease (2). Systemic therapeutic strategies for advanced RCC include surgical management, chemotherapy, radiotherapy, immunotherapy and molecular targeted therapy (3-5). Following nephrectomy, $20 \%$ of patients will suffer a relapse and develop metastatic (m)RCC (6). Cytotoxic chemotherapy has consistently failed to benefit patients (7) and RCC has been identified as being intrinsically radioresistant (8). Molecular targeted therapy may prolong the life of patients, although they often acquire resistance over time $(9,10)$. In addition, adverse side-effects are often associated with the treatment, including rashes, diarrhea, edema and weight gain (11).

Since the prognosis is poor for patients with advanced RCC or mRCC, there is an urgent demand for further prognostic improvements. As RCC is an immunogenic tumour, it is a putative target for immunotherapeutic intervention strategies (12). Interferon (IFN)- $\alpha$ is an immunotherapeutic agent generated predominantly by monocytes and macrophages, which elicit beneficial effects on human health in a variety of ways. Previous studies revealed that IFN- $\alpha$ modulates the immune response (13), induces apoptosis (14) and directly inhibits the proliferation $(15,16)$ and differentiation of tumour cells (17). As a type I IFN, IFN- $\alpha$ has been used clinically. In addition, IFN- $\alpha$ was recommended as a first-line treatment for clear-cell mRCC in systemic therapy; however, the therapeutic effects of IFN- $\alpha$ monotherapy are limited in duration (18).

The cancer immunoediting theory, which hypothesizes that malignancy results from the imbalance between immunosurveillance and tumour immune escape (19), has reinvigorated much research effort in the field of cancer immunology. Previous studies have revealed that myeloid-derived suppressor cells (MDSCs) are one of the key drivers of tumour-mediated immune evasion. MDSCs promote tumour growth via different mechanisms $(20,21)$, and consequently, MDSCs exert a clear 
prognostic importance in multiple solid tumour types. Newly acquired data support the suitability of circulating MDSCs as a predictive marker for cancer immunotherapy (22).

Lycium barbarum (Goji berry) has been used in China for 2,000 years. L. barbarum polysaccharides (LBP), derived from the water-soluble portion of extract from L. barbarum, are important bioactive compounds. Previous studies have suggested that LBP may exert a role in a variety of biological processes, including immunomodulation, as an anticancer agent, in enhancing metabolism and in the amelioration of physical fatigue $(23,24)$. Furthermore, novel data revealed that LBP may activate T-cells (25), increase macrophage phagocytosis (26), stimulate the phenotypic maturation of dendritic cells (DCs) with marked immunogenicity (27) and arrest the cell cycle of tumour cells (28). Additionally, a polysaccharide-protein complex markedly suppressed the growth of transplantable sarcomas and enhanced the action of macrophages (26); however, the precise effects of LBP on RCC cells and the underlying molecular mechanisms remain to be elucidated.

In the present study the effects and the mechanism of LBP in combination with IFN- $\alpha 2 b$ on the murine RCC Renca cell line in vitro and on renal tumour xenografts in vivo were analyzed to provide a basis for the clinical use of LBP and recombinant human IFN- $\alpha 2 b$ in patients with RCC.

\section{Materials and methods}

Murine RCC cell line and cell culture. The murine RCC cell line, Renca, was purchased from Shanghai Cell Bank (Shanghai Xin Yu Biotech Co., Ltd, Shanghai, China). The cells were grown in RPMI-1640 media (Gibco Life Technologies, Carlsbad, CA, USA), including $10 \%$ fetal bovine serum (FBS; HyClone, GE Healthcare Life Sciences, Logan, UT, USA), $100 \mathrm{U} / \mathrm{ml}$ penicillin and $100 \mu \mathrm{g} / \mathrm{ml}$ streptomycin (Gibco Life Technologies) at $37^{\circ} \mathrm{C}$ in a humidity-controlled incubator with $5 \% \mathrm{CO}_{2}$.

Cell viability assay. The Renca cells $\left(3.0 \times 10^{3}\right.$ cells/well) were seeded into 96-well plates, cultured for $24 \mathrm{~h}$ and stimulated with either fresh RPMI-1640 culture medium, containing either $10 \%$ FBS (control), IFN- $\alpha 2 b(1,000,2,000,4,000$ or 8,000 IU/ml; Furen Pharmaceutical Group Co., Ltd., Beijing, China) or LBP (50, 100, 200 or $400 \mu \mathrm{g} / \mathrm{ml}$; 70\% purity, Xian Plant Bio-Engineering Co., Ltd., Xian, China) for 24, 48 and $72 \mathrm{~h}$. A total of $20 \mu 10.5 \mathrm{mg} / \mathrm{ml}$ MTT solution (Ameresco, Inc., Framingham, MA, USA) was added to each well, incubated for $4 \mathrm{~h}$ and subsequently the culture medium was replaced with $150 \mu \mathrm{l} /$ well dimethyl sulfoxide (Sigma-Aldrich, St. Louis, MO, USA). The cells were agitated for $10 \mathrm{~min}$ to dissolve the purple crystals. The absorbance (A) at $570 \mathrm{~nm}$ was analyzed using a microplate reader (680; Bio-Rad Laboratories, Hercules, CA, USA). The cell viability rate (\%) was quantified as follows: $\left(\mathrm{A}_{\text {treated }}\right) /\left(\mathrm{A}_{\text {control }}\right) \times 100 \%$.

Subsequently,theRencacells $\left(3.0 \times 10^{3}\right.$ cells/well $)$ wereseeded into 96-well plates and cultured for $24 \mathrm{~h}$ in fresh RPMI-1640 culture medium, containing $10 \%$ FBS (control), IFN- $\alpha 2 b$ $(4,000 \mathrm{IU} / \mathrm{ml}), \mathrm{LBP}(200 \mathrm{mg} / \mathrm{ml})$ or IFN- $\alpha 2 \mathrm{~b}(4,000 \mathrm{IU} / \mathrm{ml})$ in combination with LBP $(200 \mathrm{mg} / \mathrm{ml})$. The cells were cultured for 24,48 or $72 \mathrm{~h}$, and the remaining stages were performed, as described above. Each experiment was repeated three times with four wells for each concentration.

Apoptosis assay. The Renca cells (2x10 $/$ well) were seeded into 6-well plates and following overnight attachment, were treated with either $10 \%$ FBS (control), IFN- $\alpha 2 b(4,000 \mathrm{IU} / \mathrm{ml})$, LBP $(200 \mu \mathrm{g} / \mathrm{ml})$ or IFN- $\alpha 2 \mathrm{~b}(4,000 \mathrm{IU} / \mathrm{ml})$ in combination with LBP $(200 \mu \mathrm{g} / \mathrm{ml})$, for $48 \mathrm{~h}$. The cells were collected by centrifugation at $1,000 \mathrm{rpm}$ for $5 \mathrm{~min}$ at $37^{\circ} \mathrm{C}$. The collected cells were washed with ice-cold phosphate buffered saline (PBS) and $1 \mathrm{X}$ binding buffer (BD Biosciences, Franklin Lakes, NJ, USA). Subsequently, a $100 \mu \mathrm{l}$ suspension solution containing $5 \mu \mathrm{l}$ annexin V-fluorescein isothiocyanate (FITC; BD Biosciences) and $5 \mu$ l propidium iodide (PI; Sigma-Aldrich) were incubated at room temperature in the dark for $15 \mathrm{~min}$. Subsequently, $500 \mu 1 \mathrm{X}$ binding buffer was added and the samples were measured using a FACSVantage SE flow cytometer (BD Biosciences). CellQuest software (BD Biosciences) was used to analyze the flow cytometry data.

Cell cycle analysis. Renca cells stimulated, as described above for the apoptosis assay for $48 \mathrm{~h}$, were treated with trypsin, centrifuged at $800 \mathrm{rpm}$ for $5 \mathrm{~min}$ at $37^{\circ} \mathrm{C}$ and fixed with pre-chilled $75 \%$ ethanol for $>18 \mathrm{~h}$ at $4^{\circ} \mathrm{C}$. Following treatment with $1 \%$ ribonuclease A (Sigma-Aldrich) for $30 \mathrm{~min}$ at $37^{\circ} \mathrm{C}$, the cells were stained with $50 \mu \mathrm{g} / \mathrm{ml}$ PI for $30 \mathrm{~min}$ at $4^{\circ} \mathrm{C}$. A BD FACSVantage SE flow cytometer was used to examine the cell cycle distribution at $490 \mathrm{~nm}$. The proportion of cells in each cycle were analyzed using multicycle DNA content and CellQuest cell analysis software. Each experiment was performed in triplicate.

Western blot analysis. Following seeding the Renca cells $\left(1 \times 10^{6}\right)$ into a culture flask, the cells were treated, as described for the apoptosis assay, for $48 \mathrm{~h}$. The cells were subsequently lysed in radioimmunoprecipitation assay buffer (Beijing ComWin Biotech Co., Ltd., Beijing, China), containing protease inhibitor, phenylmethylsulfonyl fluoride, and incubated for $30 \mathrm{~min}$ on ice. The lysates were ultracentrifuged at $13,800 \mathrm{x}$ g for $15 \mathrm{~min}$ at $4^{\circ} \mathrm{C}$ and the supernatant was collected. The protein concentration was measured using the bicinchoninic acid method (Beyotime Institute of Biotechnology, Haimen, China). The protein lysates $(30 \mu \mathrm{g})$ were separated by SDS-polyacrylamide gel electrophoresis (Beyotime Institute of Biotechnology) and were transferred onto polyvinylidene difluoride membranes (Amersham Biosciences, Beijing, China) using a wet transfer apparatus. Non-fat milk (5\%) was used to block the membranes for $1 \mathrm{~h}$ at room temperature, then the membranes were incubated with primary antibodies overnight at $4{ }^{\circ} \mathrm{C}$. The antibodies were as follows: Rabbit monoclonal anti-Bcl-2 (1:1,000; cat. no. sc-492), anti-Bax (1:1,000; cat. no. sc-526), anti-cyclin D1 (1:1,000; cat. no. sc-718) and anti-c-Myc (1:1,000; cat. no. sc-764; Santa Cruz Biotechnology, Inc., Santa Cruz, CA, USA), and rabbit polyclonal anti-glyceraldehyde-3-phosphate dehydrogenase (GAPDH; cat. no. sc-25778; $1: 5,000)$. Subsequently, the membranes were incubated with a 1:2,000 dilution of horseradish peroxidase-labelled secondary antibody (cat. no. CW0103; Beijing ComWin Biotech Co., Ltd.) for $1 \mathrm{~h}$. The protein bands were analyzed using enhanced chemiluminescence (Beijing ComWin Biotech Co., Ltd.) and 
an Odyssey Two-Color Infrared Imaging system (LI-COR Bioscience, Inc., Lincoln, NE, USA). The blots were re-probed and incubated with anti-GAPDH as a loading control for protein normalization.

Mouse xenograft model treatment. Animal experiments were performed on the basis of the institutional animal care and use committee guidelines at Chongqing Medical University (Chongqing, China). The study was approved by the ethics committee of the First Affiliated Hospital of Chongqing Medical University. A total of 28 male BALB/c mice, aged 4 weeks, were obtained from the Experimental Animal Center of Chongqing Medical University (Chongqing, China) and were fed on a standard sterile laboratory diet for $>3$ days prior to experiments. The mice were housed 5 per cage in a temperature, humidity, and light/dark cycles-controlled room (temperature: $22 \pm 2^{\circ} \mathrm{C}$, humidity: $60 \%, 12 \mathrm{~h}$ light/dark cycles) with ad libitum access to food and water. The weight of the mice was $15 \pm 0.36 \mathrm{~g}$. Renca cells $\left(2 \times 10^{6}\right)$ mixed $1: 1$ with Matrigel (BD Biosciences) in $100 \mu \mathrm{l}$ PBS were injected subcutaneously into each mouse. When the tumour size reached $40-50 \mathrm{~mm}^{3}, 28$ mice were selected and randomly assigned to either the control, IFN- $\alpha 2 b$, LBP or IFN- $\alpha 2 b$ in combination with LBP groups. IFN- $\alpha 2 b$ was dissolved in sterile PBS prior to injection and LBP were diluted in sterile PBS for oral administration. IFN- $\alpha 2 b(200 \mathrm{IU} / \mathrm{g})$ was administered by intraperitoneal injection twice weekly for 15 days and LBP were administered by gavage at dosages of $20 \mu \mathrm{g} / \mathrm{g}$ once daily for 15 days. The control and the IFN- $\alpha 2 b$ alone groups were administered $100 \mu 1$ sterile PBS by gavage, and the control and the LBP alone groups were administered $100 \mu$ l sterile PBS by intraperitoneal injection. The tumour sizes were measured using callipers twice weekly and counted as follows: $\pi / 6 \mathrm{x}$ large diameter $\mathrm{x}$ (small diameter) ${ }^{2}$. The body weights were measured twice weekly. On the day following the completion of the 15 day treatment, the animals were sacrificed via cervical dislocation and the tumors were carefully resected, weighed, measured and stored at $-80^{\circ} \mathrm{C}$.

Detection of the CDIIb $\mathrm{Gr}^{+} \mathrm{I}^{+}$cells from murine bone marrow using flow cytometry and confocal laser scanning microscopy. The femurs and tibias were obtained immediately after the four groups of male BALB/c mice were sacrificed, from which isolated bone marrow cells were labelled using the FITC anti-mouse Ly-6G/Ly-6C and PE anti-mouse CD11b antibodies (Tianjin Sungene Biotech Co., Ltd., Tianjin, China). The cells were subsequently incubated for $30 \mathrm{~min}$ at $4^{\circ} \mathrm{C}$ in the dark. Following two washes, the cells were analyzed using the BD FACSAriaTMII Special Order system (BD Biosciences) and a Leica TCS SP2 laser scanning confocal microscope (Leica, Mannheim, Germany).

Statistical analysis. Statistical analyses were performed using SPSS 17.0 software (SPSS, Inc., Chicago, IL, USA). The data are expressed as the mean \pm standard deviation. Multiple comparisons in the interblock were analyzed using a one-way analysis of variance test, and individual comparisons were analyzed using Fisher's least significance difference post-hoc test between the control and treatment groups. $\mathrm{P}<0.05$ was considered to indicate a statistically significant difference.

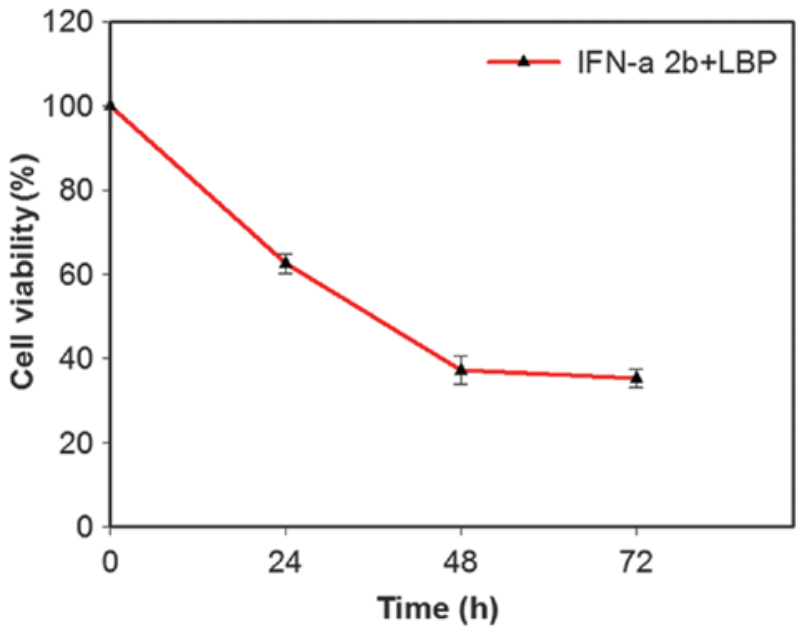

Figure 1. Effect of IFN- $\alpha 2 b$ in combination with LBP on the suppression of Renca cell viability. The effect of IFN- $\alpha 2 b$ plus LBP on cell viability was measured using an MTT assay. The Renca cells were treated with IFN- $\alpha 2 b$ $(4,000 \mathrm{IU} / \mathrm{ml})$ plus LBP $(200 \mu \mathrm{g} / \mathrm{ml})$ for 24,48 and $72 \mathrm{~h}$. IFN- $\alpha 2 \mathrm{~b}$ in combination with LBP significantly inhibited Renca cell viability at $48 \mathrm{~h}$ in a time-dependent manner. The data are expressed as the mean \pm standard deviation of three independent experiments $\left({ }^{* *} \mathrm{P}<0.01\right)$. IFN- $\alpha 2 b$, interferon- $\alpha 2 b$; LBP, L. barbarum polysaccharides.

\section{Results}

Inhibition of cell proliferation following treatment with LBP and IFN- $\alpha 2 b$ in the Renca cells. To investigate the role of LBP and IFN- $\alpha 2 b$ on the proliferation of the Renca cells, the cells treated with LBP and IFN- $\alpha 2 b$ were assessed using an MTT assay. To confirm the mode of action of IFN- $\alpha 2 b$ or LBP alone, and their use in combination, in Renca cells, the absorption was detected at various concentrations and durations. The cell viability rate was subsequently calculated using the above-mentioned equation.

The dose-effect curve demonstrated an effect $48 \mathrm{~h}$ following the addition of IFN- $\alpha 2 b$ at a concentration of $4,000 \mathrm{IU} / \mathrm{ml}$ and of LBP at a concentration of $200 \mu \mathrm{g} / \mathrm{ml}$, whereby the viability of the Renca cells was significantly inhibited. Therefore concentrations of $4,000 \mathrm{IU} / \mathrm{ml}$ IFN- $\alpha 2 b$ and $200 \mu \mathrm{g} / \mathrm{ml}$ LBP were selected for subsequent experiments. IFN- $\alpha 2 \mathrm{~b}(4,000 \mathrm{IU} / \mathrm{ml})$ in combination with LBP $(200 \mu \mathrm{g} / \mathrm{ml})$ significantly inhibited the cell proliferation in a time-dependent manner ${ }^{* *} \mathrm{P}<0.01$; Fig. 1$)$. The viability of the cells was reduced to $37.0 \%$ following this treatment for $48 \mathrm{~h}$. The Renca cells were treated with different concentrations of IFN- $\alpha 2 b$ alone $(1,000,2,000,4,000$ and $8,000 \mathrm{IU} / \mathrm{ml})$ for $48 \mathrm{~h}$, and the cell viability was $79 \pm 1.40,61 \pm 1.30,40 \pm 1.30$ and $50 \pm 1.24 \%$, respectively. The Renca cells were treated with different concentrations of LBP alone (50, 100, 200 and $400 \mu \mathrm{g} / \mathrm{ml})$ for $48 \mathrm{~h}$, and the cell viability was $72 \pm 1.51,60 \pm 1.21,41 \pm 1.23$ and $50 \pm 1.11 \%$, respectively.

Combination treatment with $L B P$ and IFN- $\alpha 2 b$ promotes the apoptosis of Renca cells. To determine the effect of LBP and IFN- $\alpha 2 b$ on apoptosis in Renca cells, the percentage of cells undergoing apoptosis was confirmed and quantified using an annexin V-FITC/PI assay. The percentages featured in the lower right and upper right quadrant of the histograms 
Table I. Renca cell cycle phases stimulated by IFN- $\alpha 2 \mathrm{~b}$ or LBP alone or in combination for $48 \mathrm{~h}$.

\begin{tabular}{lccr}
\hline Group & G0/G1 $(\%)$ & $\mathrm{S}(\%)$ & $\mathrm{G} 2 / \mathrm{M}(\%)$ \\
\hline Control & $35.4430 \pm 0.9710^{\mathrm{a}}$ & $54.3030 \pm 2.1500^{\mathrm{a}}$ & $12.693 \pm 0.774$ \\
IFN- $\alpha 2 \mathrm{~b}$ & $47.6160 \pm 0.3610^{\mathrm{a}}$ & $46.0430 \pm 0.7670^{\mathrm{a}}$ & $6.336 \pm 0.80$ \\
LBP & $57.0900 \pm 0.2950^{\mathrm{a}}$ & $37.780 \pm 0.6238^{\mathrm{a}}$ & $4.32 \pm 0.353$ \\
IFN- $\alpha 2 \mathrm{~b}+$ LBP & $67.8160 \pm 0.5080^{\mathrm{a}}$ & $21.1060 \pm 0.4636^{\mathrm{a}}$ & $14.37 \pm 5.637$
\end{tabular}

The data indicate the mean \pm standard deviation $\left({ }^{\mathrm{a}} \mathrm{P}<0.01\right)$. IFN- $\alpha 2 \mathrm{~b}$, interferon- $\alpha 2 \mathrm{~b}$; LBP, L. barbarum polysaccharides.

A
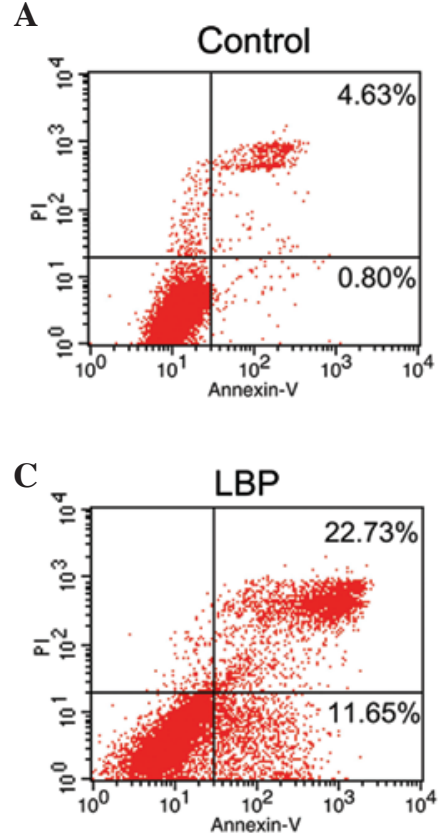

B

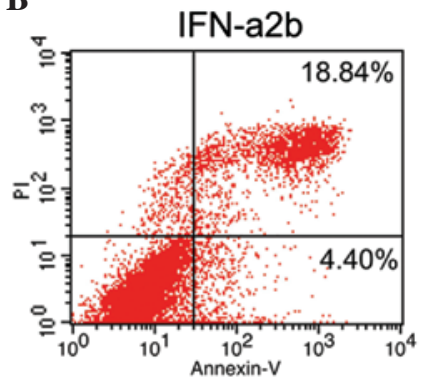

D

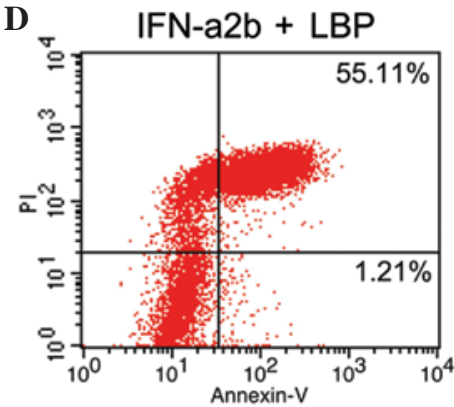

$\mathbf{E}$

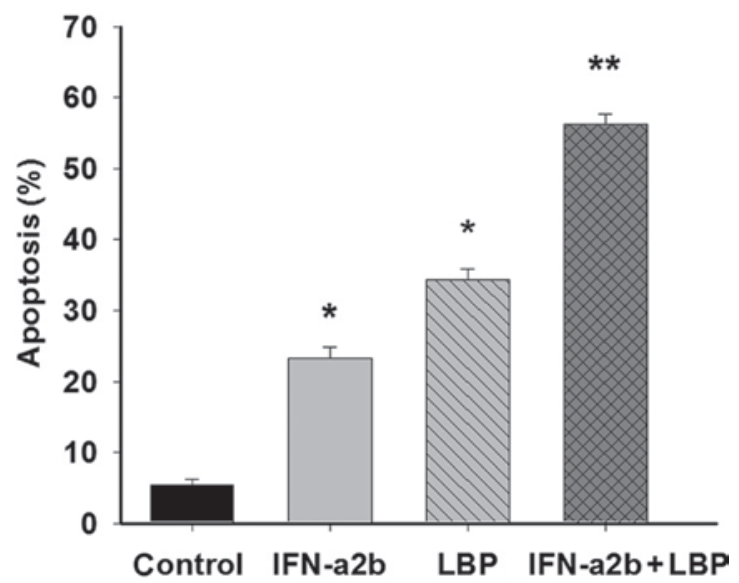

Figure 2. IFN- $\alpha 2 b$, in combination with LBP, promotes apoptosis in Renca cells. The Renca cells were (A) non-treated or treated with (B) IFN- $\alpha 2 b$ (4,000 IU/ml), (C) LBP $(200 \mu \mathrm{g} / \mathrm{ml})$ or (D) IFN- $\alpha 2 \mathrm{~b}$ plus LBP for $48 \mathrm{~h}$ prior to staining with fluorescein isothiocyanate-annexin V and PI. The percentage of surviving cells was indicated in the lower left panel of the quadrant. The percentages indicated in the lower right and upper right quadrant of the histograms represent the early and late apoptotic cells, respectively. (E) The percentages of cells undergoing apoptosis induced by IFN- $\alpha 2 \mathrm{~b}(4,000 \mathrm{IU} / \mathrm{ml}), \mathrm{LBP}(200 \mu \mathrm{g} / \mathrm{ml}) \mathrm{and}$ IFN- $\alpha 2 \mathrm{~b}$ plus LBP were quantified. The data are expressed as the mean \pm standard deviation ( $\left({ }^{*}<0.05\right.$, vs. control; ${ }^{* *} \mathrm{P}<0.01$, vs. the IFN- $\alpha 2 \mathrm{~b}$ or LBP groups alone). IFN- $\alpha 2 \mathrm{~b}$, interferon- $\alpha 2 b$; LBP, $L$. barbarum polysaccharides; PI, propidium iodide.

represent the early and late apoptotic cells, respectively. Following treatment of the cells, as described above for $48 \mathrm{~h}$, the total percentage of apoptotic cells was $23.26,34.39$ and $56.37 \%$ in the IFN- $\alpha 2 b, \mathrm{LBP}$ and IFN- $\alpha 2 \mathrm{~b}$ in combination with LBP groups, respectively, compared with the control group (5.43\%; ${ }^{*} \mathrm{P}<0.05$ and ${ }^{* *} \mathrm{P}<0.01$; Figs. $\left.2 \mathrm{~A}-\mathrm{E}\right)$. The results demonstrated the anticancer effect of IFN- $\alpha 2 b$ in combination with LBP in the Renca cells. 
A

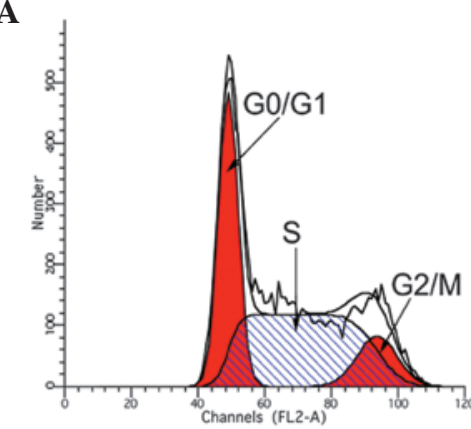

C

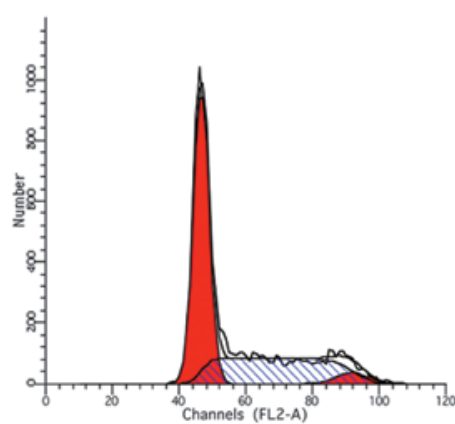

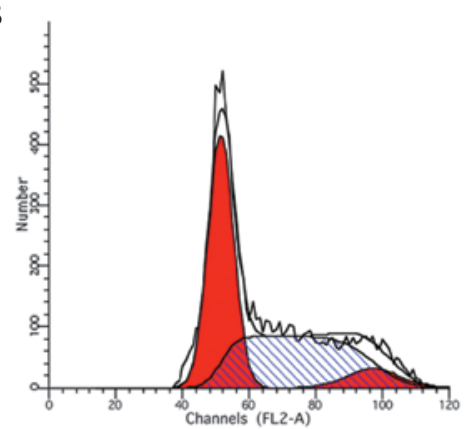

D

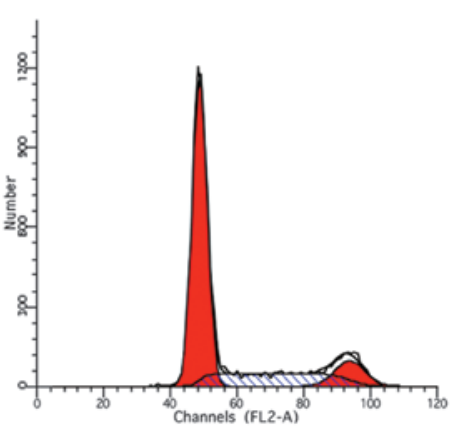

Figure 3. Effect of IFN- $\alpha 2$ b alone or in combination with LBP on the Renca cell cycle. (A) The non-treated cells (control) exhibited a normal cell cycle pattern. The flow cytometric analysis revealed the presence of an increased number of cells in the G0/G1 phase and a decreased number in the S and G2 phases in Renca cells stimulated with (B) IFN- $\alpha 2 \mathrm{~b}$ alone $(4,000 \mathrm{IU} / \mathrm{ml})$ or (C) LBP alone $(200 \mu \mathrm{g} / \mathrm{ml})$ for 48 h compared with the control. However, the number of Renca cells arrested in the G0/G1 and G2 phases increased, whereas those in the S phase decreased, following stimulation with (D) IFN- $\alpha 2 b$ and LBP in combination for $48 \mathrm{~h}$ compared with the control group. G, growth phase; IFN- $\alpha 2 \mathrm{~b}$, interferon- $\alpha 2 \mathrm{~b}$; LBP, L. barbarium polysaccharides; S, synthesis phase.

Treatment with LBP and IFN- $\alpha 2 b$ arrests the Renca cell cycle. Treatment with IFN- $\alpha 2 \mathrm{~b}$ and LBP inhibited Renca cell growth, which was always associated with cell cycle arrest. Following treatment of the Renca cells with either IFN- $\alpha 2 b$, LBP or IFN- $\alpha 2 b$ in combination with LBP for $48 \mathrm{~h}$, flow cytometry was performed. The results revealed that the combined treatment of the cells with IFN- $\alpha 2 b$ and LBP resulted in a more marked accumulation in the G0/G1 phase compared with that of the control $(\mathrm{P}<0.01$; Table I and Fig. 3).

Effect of LBP and IFN- $\alpha 2 b$ on the expression of Renca cell-associated proteins. Cyclin D1, one of the critical cell cycle regulators, promotes the G1/S-phase transition and induces cell proliferation. c-Myc also influences cell cycle regulation, as the overexpression of c-Myc stimulates cell cycle progression, whereas c-Myc downregulation exerts the opposite effect. Bcl-2 protein inhibits target cell apoptosis, whereas the protein Bax enhances target cell apoptosis. Following the treatment of the Renca cells with either IFN- $\alpha 2 b$, LBP or IFN- $\alpha 2 b$ in combination with LBP for $48 \mathrm{~h}$, the expression levels of the above proteins were measured by western blot analysis (Fig. 4A). The results revealed that cyclin D1, c-Myc and $\mathrm{Bcl}-2$ were downregulated, whereas Bax was upregulated, in all treatment groups compared with the control group, and more significant changes were identified in the IFN- $\alpha 2 b$ in combination with LBP group (Figs. 4B-E).

Combined treatment with LBP and IFN- $\alpha 2 b$ inhibits tumour growth in a Renca xenograft model. To further determine whether IFN- $\alpha 2 b$ in combination with LBP inhibits tumour growth in vivo, BALB/c mice bearing Renca tumour xenografts were treated with either IFN- $\alpha 2 b, \mathrm{LBP}$ or IFN- $\alpha 2 b$ in combination with LBP for 15 days. The doses of drugs used were determined according to a previous study (29). Compared with the control BALB/c mice (Fig. 5A), those treated with IFN- $\alpha 2 b$ (Fig. 5B) and LBP (Fig. 5C) exhibited a significantly smaller tumour volume. In addition, compared with the groups receiving monotherapy, the tumour volumes in the combination group xenografts (Fig. 5D) were markedly smaller. In conclusion, the data indicated that the antitumor efficacy of LBP combined with IFN- $\alpha 2 b$ is greater compared with LBP and IFN- $\alpha 2 b$ alone (Fig. 5E).

Effect of combination treatmetn with LBP and IFN- $\alpha 2 b$ on the $C D 1 \mathrm{lb}^{+} \mathrm{Gr}-\mathrm{I}^{+}$cells in the bone marrow of tumour-bearing

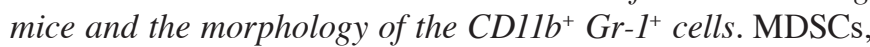
which facilitate tumour growth, are one of the crucial negative immune regulators. MDSCs were defined as $\mathrm{CD} 11 \mathrm{~b}^{+} \mathrm{Gr}-1^{+}$cells in the mouse. The morphology of the MDSCs was examined using confocal laser scanning microscopy (Fig. 6A). To determine the mechanism of IFN- $\alpha 2 b$ and LBP on Renca cells in vivo, the proportion of MDSCs in the bone marrow cells from $\mathrm{BALB} / \mathrm{c}$ mice bearing Renca tumour xenografts were gated. The tumour-bearing mice were treated with either IFN- $\alpha 2 b$, LBP or IFN- $\alpha 2 b$ in combination with LBP for 15 days. The results revealed that the percentages of $\mathrm{CD}_{11} \mathrm{~b}^{+} \mathrm{Gr}-1^{+}$bone marrow cells were clearly reduced in the treatment groups compared with the control group (Fig. 6B; ${ }^{*} \mathrm{P}<0.05$ ). Compared with IFN- $\alpha 2 b$ alone (Fig. 6C) and LBP alone (Fig. 6D) groups, the reduction was more pronounced in the tumour-bearing mice treated with IFN- $\alpha 2$ b plus LBP (Fig. $6 \mathrm{E} ;{ }^{* *} \mathrm{P}<0.01$ ). No significant reduction was observed between the IFN- $\alpha 2 b$ and LBP alone groups. 
A

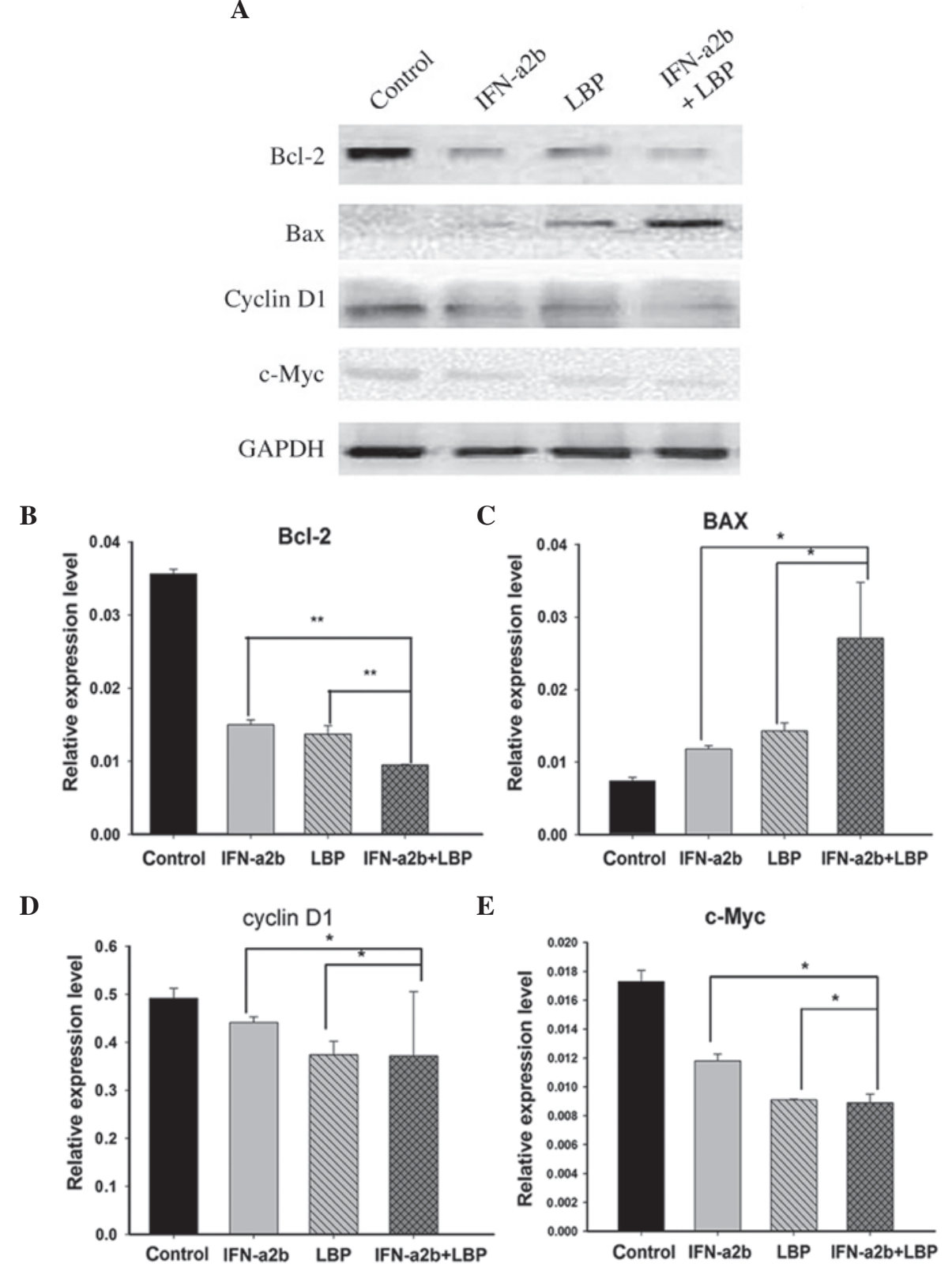

Figure 4. Effect of IFN- $\alpha 2 \mathrm{~b}$ and LBP on protein expression levels. (A) The effects of IFN- $\alpha 2 \mathrm{~b}(4,000 \mathrm{I} \mathrm{U} / \mathrm{ml})$ and LBP (200 $\mu \mathrm{g} / \mathrm{ml})$ on the expression levels of cell cycle-associated proteins (cyclin D1 and c-Myc) and cell apoptosis-associated proteins (Bcl-2 and Bax) were investigated by western blot analysis. The data are representative of three independent experiments. (B-E) The intensity of the bands was normalized against the internal standard, GAPDH, and the results are shown for (B) Bcl-2, (C) BAX, (D) cyclin D1 and (E) c-Myc as a ratio against the control. The data are expressed as the mean \pm standard deviation ("P $<0.05$, ${ }^{* *} \mathrm{P}<0.01$, vs. the IFN- $\alpha 2 \mathrm{~b}$ alone and LBP alone groups). GAPDH, glyceraldehyde -3 -phosphate dehydrogenase, IFN- $\alpha 2 \mathrm{~b}$, interferon- $\alpha 2 \mathrm{~b}$; LBP, L. barbarium polysaccharides.

\section{Discussion}

In the present study, the results revealed that the synergistic immunotherapeutic effects of LBP in combination with IFN- $\alpha 2 b$ inhibited the proliferation of mouse RCC Renca cells in vitro and in vivo.

RCC is considered to be an immunogenic tumour, for which immunotherapy is one of the systemic therapies. As a multifunctional cytokine, IFN- $\alpha$ intervenes in tumour cell proliferation and apoptosis, and has been used in the treatment of various malignancies. A previous study determined that cell growth was inhibited by treatment with recombinant human IFN- $\alpha 1 b$ in human nasopharyngeal carcinoma (15). IFN- $\alpha$ markedly inhibits the growth of the pheochromocytoma PC12 line and increases apoptosis (16). Booy et al (30) identified that IFN- $\alpha$ significantly reduces cell growth in eight human pancreatic cancer cell lines. Since the short duration of therapeutic effects and immunotherapeutic efficacy of IFN- $\alpha$ are limited, novel therapeutic strategies for advanced RCC are required.

LBP perform numerous roles, including in immunomodulation and anticancer functions. Previous studies identified that LBP inhibit the proliferation of human QGY7703 hepatoma cells (29), and human MGC-803 and SGC-7901 gastric cancer cells (28). Since IFN- $\alpha$ and LBP operate according to different mechanisms of action in tumour cells, their combined use may 

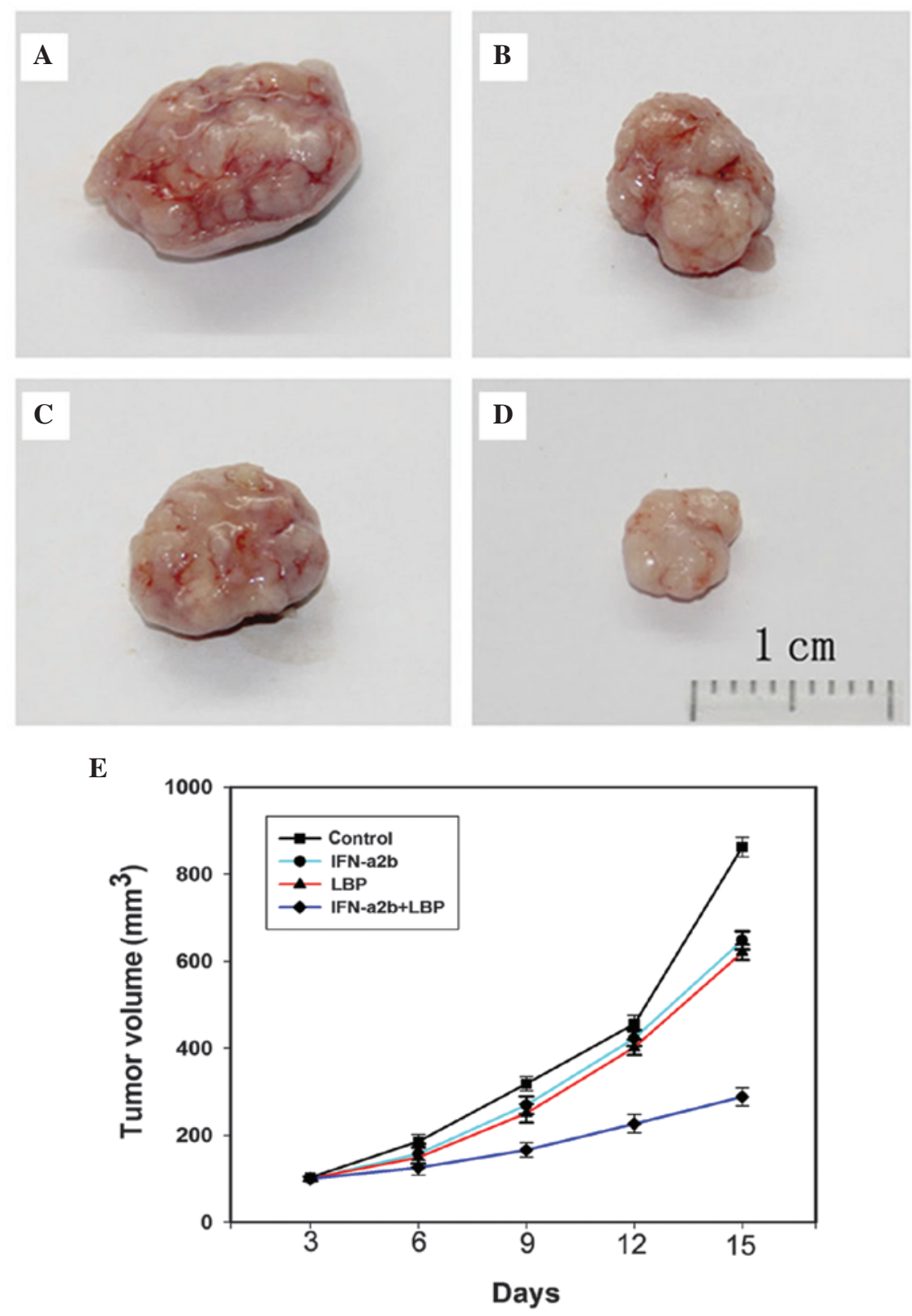

Figure 5. LBP and IFN- $\alpha 2 b$ inhibit the growth of Renca cell tumour xenografts. The images of the excised tumours were captured from the (A) control, (B) IFN- $\alpha 2 b$, (C) LBP and (D) IFN- $\alpha 2 b$ plus LBP-treated groups. (E) A graph representing the average tumour volumes of Renca xenografts from the control, IFN- $\alpha 2 b$ alone, LBP alone and IFN- $\alpha 2 b$ plus LBP groups. The data are presented as the mean \pm standard deviation. IFN- $\alpha 2 b$, interferon- $\alpha 2 b ;$ LBP, L. barbarum polysaccharide

potentially offer novel treatment options for RCC; however, the effect and mechanism of LBP and IFN- $\alpha 2 b$ in combination therapy remains to be elucidated.

To investigate the combined effects of LBP and IFN- $\alpha 2 b$ in RCC cell lines, the effects of IFN- $\alpha 2 b$ and LBP on cell viability were initially measured. An MTT assay revealed that there was a marked decrease in cell viability in the Renca cells treated with IFN- $\alpha 2 b$ or LBP alone; however, cell viability was markedly diminished by co-treatment with LBP and IFN- $\alpha 2 b$ for $48 \mathrm{~h}$. From these observations, co-treatment with IFN- $\alpha 2 b$ and LBP appears to be more effective against Renca cell proliferation in vitro compared with treatment with IFN- $\alpha 2 b$ or LBP alone.

Data have suggested that the antitumor effects of immunotherapeutic drugs are associated with the cell cycle. A previous study demonstrated that T-cells were arrested in the G1-phase by recombinant human IFN- $\alpha 1 b$ in human nasopharyngeal carcinoma (15). Maeda et al (14) also reported that IFN- $\alpha$ induces cell cycle arrest in the G0/G1 phase in the $\mathrm{HuH7}$ hepatocellular carcinoma cell line.

To elucidate the inhibitory mechanisms of LBP and IFN- $\alpha 2 b$ in Renca cells, flow cytometric analysis was used to detect the changes in the cell-cycle distribution. The results revealed that the number of Renca cells in the G0/G1 phase were increased following drug treatment. In particular, the ratio of G0/G1 was increased more markedly compared with IFN- $\alpha 2 b$ or LBP alone. These results were consistent with previous reports using IFN- $\alpha$ treatment in RCC (31), human MGC-803 gastric cancer (28) and human SW480 and Caco-2 colon cancer (32) cells. However, DNA synthesis in 
A
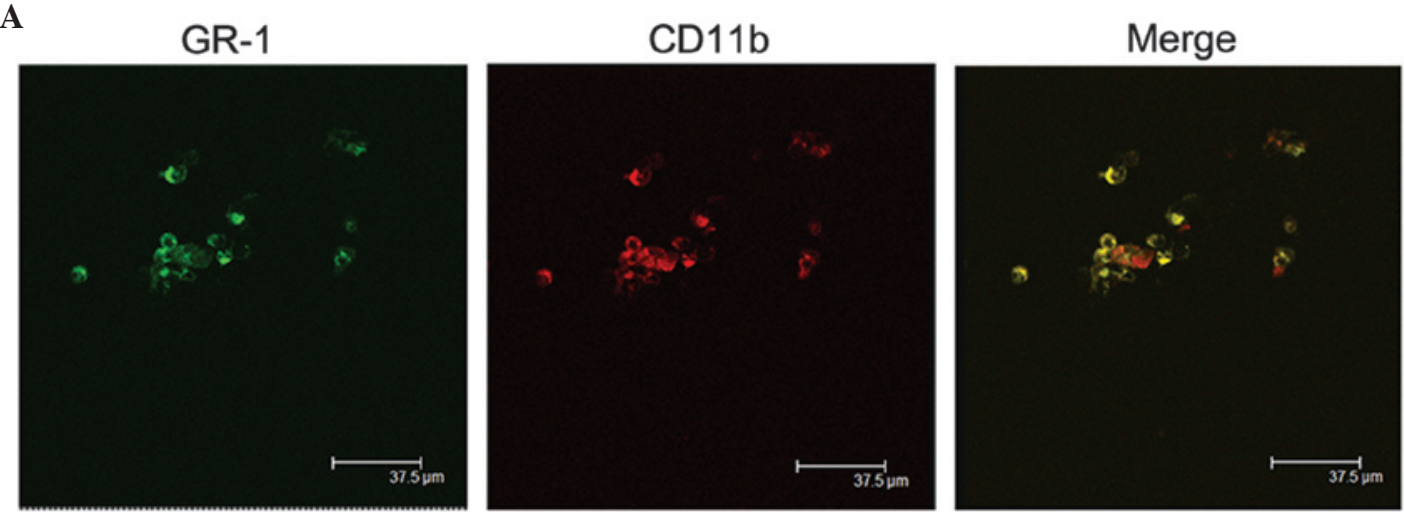

B

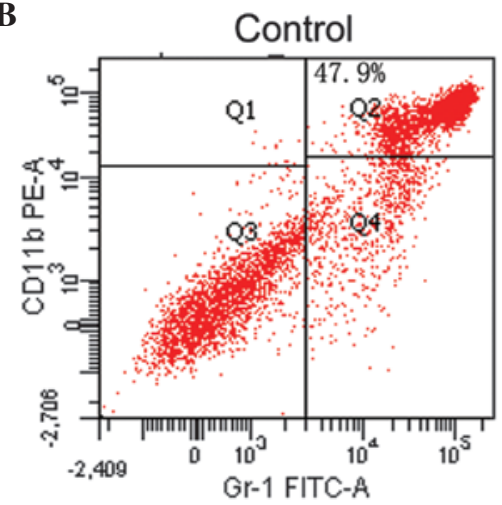

D

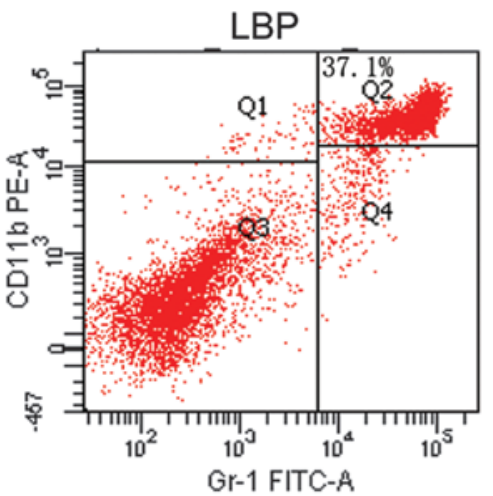

C
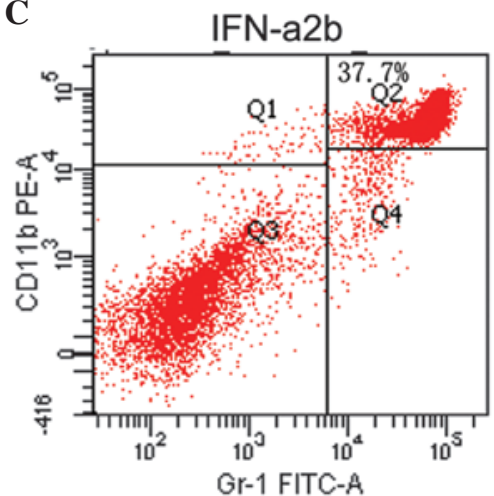

$\mathbf{E}$

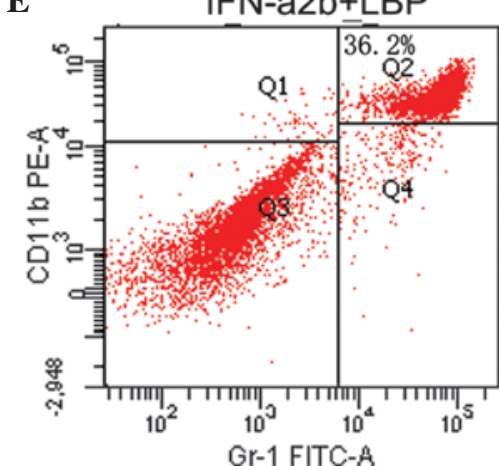

F

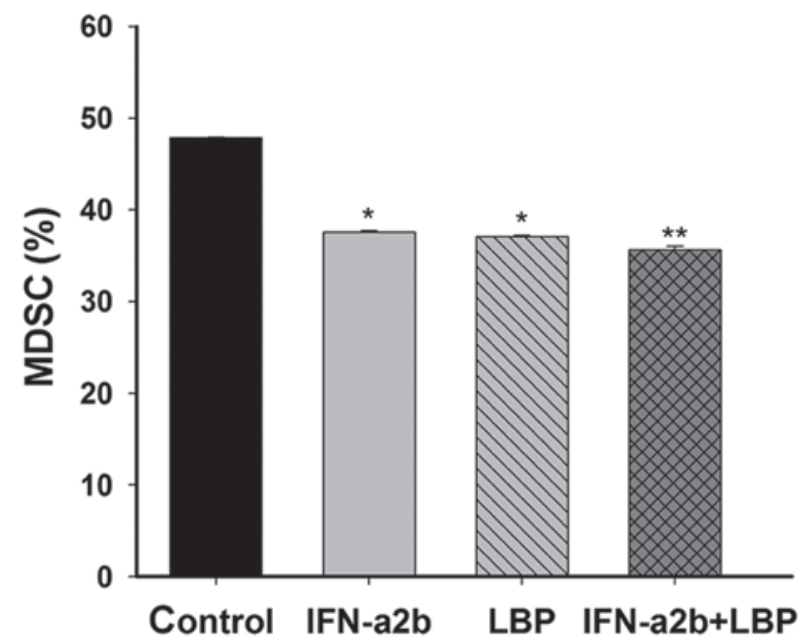

Figure 6. Effect of LBP and IFN- $\alpha 2 \mathrm{~b}$ on the CD11b $\mathrm{b}^{+} \mathrm{Gr}-1^{+}$cells in the bone marrow of tumour-bearing mice. (A) CD11 $\mathrm{b}^{+} \mathrm{Gr}-1^{+}$markers on marrow suspension cells were determined using confocal laser scanning microscopy (magnification, $\mathrm{x} 800$ ). (B-E) The ratios of CD11b ${ }^{+} \mathrm{Gr}-1^{+} \mathrm{MDSC}$ were determined using fluorescent-activated cell sorting. (F) The percentages of $\mathrm{CD} 11 \mathrm{~b}^{+} \mathrm{Gr}-1^{+}$bone marrow cells were clearly reduced in the treatment groups compared with the control group. This reduction was more marked in the IFN- $\alpha 2 b$ plus LBP group compared with the IFN- $\alpha 2 b$ and LBP alone groups. No significant reduction was observed between the IFN- $\alpha 2 b$ and LBP alone groups. The data are expressed as the mean \pm standard deviation $\left({ }^{*} \mathrm{P}<0.05, \mathrm{vs}\right.$. control; ${ }^{* *} \mathrm{P}<0.01 \mathrm{vs}$. IFN- $\alpha 2 \mathrm{~b}$ alone or LBP alone group. FITC, fluorescein isothiocyanate; CD, cluster of differentiation; IFN- $\alpha 2 \mathrm{~b}$, interferon $\alpha 2 \mathrm{~b}$; LBP, L. barbarium polysaccharides; MDSC, myeloid -derived suppressor cell. 
human QGY7703 hepatoma cells was affected and arrested in the S phase by LBP action (29). The mechanism of LBP in cancer cells is complicated and differences may result from comparing across varying types of cells.

With the exception of arresting the cell cycle, the effect of certain immunotherapeutic agents against cancer has been largely associated with the induction of apoptosis. Maeda et al (14) reported that IFN- $\alpha$ induces apoptosis in the human $\mathrm{HuH7}$ hepatocellular carcinoma cell line through an IFN- $\alpha$ type- 2 receptor-dependent signalling pathway. Markowitz et al (33) reported that the combined use of bortezomib and IFN- $\alpha$ synergistically induced apoptosis in human melanoma cells in melanoma tumour-bearing mice. Additionally, another previous study revealed that LBP suppresses the proliferation of HeLa cells (34) and human QGY7703 hepatoma cells by inducing apoptosis (29). In particular, apoptosis was induced to a greater extent by co-treatment with IFN- $\alpha 2 \mathrm{~b}$ or LBP compared with treatment with IFN- $\alpha 2 b$ or LBP alone. These results suggested that co-treatment with IFN- $\alpha 2 b$ and LBP suppressed Renca cell proliferation by activating apoptosis.

Emerging evidence has revealed that the cell cycle regulatory- and apoptosis-associated proteins are implicated in the anticancer activity of certain immunotherapeutic agents. To confirm the mechanism of inhibition of proliferation at the protein level, western blot analysis was performed to detect the expression of cyclin D1, c-Myc, Bcl-2 and Bax. In the G0/G1 phase, cyclin D1, which is considered to be one of the predominant cell-cycle regulators, promoted the G1-S phase transition (35). c-Myc is associated with cell cycle regulation, as the expression levels of c-Myc are tightly correlated with cell proliferation. Overexpression of c-Myc stimulates cell cycle progression, whereas Myc downregulation exerts the opposite effect. A previous study suggested that IFN- $\alpha$ inhibits the expression of c-Myc (36). In the present study, the protein expression levels of cyclin D1 and c-Myc were markedly downregulated in Renca cells following treatment with LBP and IFN- $\alpha 2 b$, which was as expected, given the known characteristics of the cell-cycle distribution. These results suggested that the combination of LBP and IFN- $\alpha 2$ b suppressed Renca cell proliferation to decrease the expression levels of cyclin D1 and c-Myc.

As a proto-oncogene, the Bcl-2 gene inhibits apoptosis. Overexpression of Bcl-2 enhances the resistance of cancer cells to the majority of cytotoxins, whereas downregulation of Bcl-2 expression has been demonstrated to improve chemosensitivity in clinical studies with various carcinomas. As a proapoptotic gene, the Bax gene exerts the opposite effects. Zitzmann et al (37) reported that type I IFN- $\alpha$ mediates apoptosis by changing the ratio of antiapoptotic Bcl-2 and Bcl-xL to the proapoptotic molecules Bak and Bax in neuroendocrine tumour cells. A previous study indicated that tumour necrosis factor- $\alpha$-induced apoptosis was further enhanced by IFN- $\alpha$ by lowering the protein expression of c-Myc in HL-60 cells (38). The expression levels of the $\mathrm{Bcl}-2$ gene were reduced, and the expression of the c-Myc gene was inhibited, by IFN- $\alpha$ in the bone marrow mononuclear cells from chronic granulocytic patients (39).

A previous study revealed that LBP mediates the expression of Bcl-2 and Bax, while inducing apoptosis in human prostate cancer cells (40), and that it also suppresses the expression of the antiapoptotic Bcl-2 gene product in human HL-60 cells (41). Gómez-Benito et al (42) also reported that IFN- $\alpha$ induced myeloma cell apoptosis via the mitochondrial route. Zhu and Zhang (34) reported that the inhibitory effect of LBP on the proliferation of HeLa cells was caused by inducing apoptosis through the mitochondrial pathway.

In the present study, the expression of $\mathrm{Bcl}-2$ was reduced and the expression of Bax was higher in the co-treatment group compared with the control or single drug treatment groups, which may be due to the downregulation of the expression of Bcl-2 at the protein level by the combined use of LBP and IFN- $\alpha 2 b$ via the mitochondrial pathway.

Subsequently, the combined effect of LBP and IFN- $\alpha 2 b$ on xenograft tumours was examined, and it was observed that the tumour volume and weight were markedly reduced by co-treatment with LBP and IFN- $\alpha 2$ b compared with the control or monotherapy groups. No apparent loss of body weight was observed in the mice treated with the drugs. From these results, it appears that combination therapy with LBP and IFN- $\alpha 2 b$ will be effective against Renca cell proliferation in vivo.

To further investigate the mechanism of this effect, the population of MDSCs in isolated bone marrow cells was measured using flow cytometry and confocal laser scanning microscopy. MDSCs are a heterogeneous population, comprising progenitor and immature myeloid cells, which are at different stages of maturation and continually differentiate into different types of mature immune cells, including macrophages, DCs and granulocytes. In the mouse, these cells are usually described as $\mathrm{CD} 11 \mathrm{~b}^{+} \mathrm{GR}-1^{+}$cells (21). MDSCs inhibit the innate and adaptive immune responses, and immunosuppression is the predominant function of MDSCs. Immune evasion is a hallmark of cancer, and MDSCs are one of the key drivers of tumour-mediated immune evasion. Preclinical data in immunosuppressed murine models suggested that MDSCs are closely associated with tumour progression and the metastatic process, independent of their immunosuppressive properties. The MDSC population promotes tumour growth (20).

Previous studies have revealed that levels of MDSCs are increased in Sokal high-risk chronic myeloid leukemia (43). IFN- $\alpha$ enhanced antitumor efficiency by modulating of the suppressor of cytokine signaling 1 function of CD4 and CD8 T-cells in the context of melanoma (13). Zoglmeier et al (44) reported that recombinant IFN- $\alpha$ diminished the suppressive abilities of MDSCs in tumour-bearing mice. Additionally, a previous study reported that LBP induce phenotypic changes and the maturation of DCs, and enhance host immunity with marked immunogenicity (45). The antitumor mechanism of LBP in $\mathrm{H} 22$-bearing mice may be exerted through increasing the numbers of $\mathrm{CD}^{+}$and $\mathrm{CD} 8^{+}$ T-cells, restoring the function of the immune system (39).

In the present study, combination treatment with LBP and IFN- $\alpha 2 b$ markedly reduced the ratio of MDSCs in vivo. This indicated that treatment with the combination may decrease the numbers of MDSCs, increase the numbers of macrophages, DCs, granulocytes and CD4 and CD8 T-cells, relieve immunosuppression, and restore innate and adaptive immunity to inhibit the process of tumour growth. However, certain limitations to the present study exist, including the use of only one type of RCC cell line and the in vivo data were generated only from Renca xenograft tumours. Therefore, the 
investigation of other RCC cell lines is required to further evaluate the clinical potential of the combined use of LBP and IFN- $\alpha 2 b$. Additionally, further investigation of the immune cells in the blood and spleen of mice is required.

In conclusion, LBP and IFN- $\alpha 2 b$ may inhibit the progression of Renca xenografts via the following mechanism: The cells were arrested in the G0/G1 phase, cell proliferation was inhibited, apoptosis was induced, MDSCs were diminished, immunosuppression was relieved, and the innate and adaptive immunity pathways were restored.

\section{Acknowledgements}

This study was supported by the National Science Foundation Research Grant of China (no. 81272572) and the Foundation of Chongqing Municipal Health Bureau (no. 2012-2-042). The authors would like to thank the Experimental Animal Center and Institute of Life Sciences of Chongqing Medical University (Chongqing, China) for providing a facility to perform the animal experiments.

\section{References}

1. Siegel R, Naishadham D and Jemal A: Cancer statistics, 2012. CA Cancer J Clin 62: 10-29, 2012

2. Gupta K, Miller JD, Li JZ, Russell MW and Charbonneau C: Epidemiologic and socioeconomic burden of metastatic renal cell carcinoma (mRCC): A literature review. Cancer Treat Rev 34: 193-205, 2008.

3. Karam JA, Rini BI, Varella L, Garcia JA, Dreicer R, Choueiri TK, Jonasch E, Matin SF, Campbell SC, Wood CG, et al: Metastasectomy after targeted therapy in patients with advanced renal cell carcinoma. J Urol 185: 439-444, 2011.

4. Paly JJ, Hallemeier CL, Biggs PJ, Niemierko A, Roeder F, Martínez-Mong R, Whitson J, Calvo FA, Fastner G, Sedlmayer F, et al: Outcomes in a multi-institutional cohort of patients treated with intraoperative radiation therapy for advanced or recurrent renal cell carcinoma. Int J Radiat Oncol Biol Phys 88: 618-623, 2014.

5. Richey SL, Tamboli P, Ng CS, Lin E, Lim ZD, Araujo JC, Jonasch E, Sharma P, Pagliaro LC and Tannir NM: Phase II trial of pemetrexed plus gemcitabine in patients with locally advanced and metastatic nonclear cell renal cell carcinoma. Am J Clin Oncol 36: 450-454, 2013.

6. Athar U and Gentile TC: Treatment options for metastatic renal cell carcinoma: A review. Can J Urol 15: 3954-3966, 2008.

7. Milowsky MI and Nanus DM: Advanced renal cell carcinoma. Curr Treat Options Oncol 2: 437-445, 2001.

8. Blanco AI, Teh BS and Amato RJ: Role of radiation therapy in the management of renal cell cancer. Cancers (Basel) 3: 4010-4023, 2011.

9. Rini BI and Atkins MB: Resistance to targeted therapy in renal-cell carcinoma. Lancet Oncol 10: 992-1000, 2009.

10. Katakami N, Atagi S, Goto K, Hida T, Horai T, Inoue A, Ichinose Y, Koboyashi K, Takeda K, Kiura K, et al: LUX-Lung 4: a phase II trial of afatinib in patients with advanced non-small-cell lung cancer who progressed during prior treatment with erlotinib, gefitinib, or both. J Clin Oncol 31: 3335-3341, 2013.

11. Smolle E, Taucher V, Petru E and Haybaeck J: Targeted treatment of ovarian cancer--the multiple - kinase - inhibitor sorafenib as a potential option. Anticancer Res 34: 1519-1530, 2014.

12. Yang JC and Childs R: Immunotherapy for renal cell cancer. $\mathrm{J}$ Clin Oncol 24: 5576-5583, 2006.

13. Guenterberg KD, Lesinski GB, Mundy-Bosse BL, Karpa VI, Jaime-Ramirez AC, Wei L and Carson WE III: Enhanced anti-tumor activity of interferon-alpha in SOCS1-deficient mice is mediated by $\mathrm{CD}^{+}$and $\mathrm{CD} 8^{+}$T-cells. Cancer Immunol Immunother 60: 1281-1288, 2011.

14. Maeda S, Wada H, Naito Y, Nagano H, Simmons S, Kagawa Y, Naito A, Kikuta J, Ishii T, TomimaruY, et al: Interferon- $\alpha$ acts on the $\mathrm{S} / \mathrm{G} 2 / \mathrm{M}$ phases to induce apoptosis in the G1 phase of an IFNAR2-expressing hepatocellular carcinoma cell line. J Biol Chem 289: 23786-23795, 2014.
15. Liu X, Lu J, He ML, i Z, Zhang B, Zhou LH, Li Q, Li G, Wang L, Tian WD, et al: Antitumor effects of interferon-alpha on cell growth and metastasis in human nasopharyngeal carcinoma. Curr Cancer Drug Targets 12: 561-570, 2012.

16. Motylewska E, Lawnicka H, Kowalewicz-Kulbat M, Sicinska P, Niedziela A, Melen-Mucha G and Stepien H: Interferon alpha and rapamycin inhibit the growth of pheochromocytoma PC12 line in vitro. Endokrynol Pol 64: 368-374, 2013.

17. Wolf B, Schwarzer A, Côté AL, Hampton TH, Schwaab T, Huarte E, Tomlinson CR, Gui J, Fisher JL, Fadul CE, et al: Gene expression profile of peripheral blood lymphocytes from renal cell carcinoma patients treated with IL-2, interferon- $\alpha$ and dendritic cell vaccine. PloS One 7: e50221, 2012.

18. Ljungberg B, Bensalah K, Canfield S, Dabestani S, Hofmann F, Hora M, Kuczyk MA, Lam T, Marconi L, Merseburger AS, Mulders P, Powles T, Staehler M, Volpe A and Bex A: EAU guidelines on renal cell carcinoma: 2014 update. Eur Urol 67: 913-924, 2015.

19. Dunn GP, Old LJ and Schreiber RD: The three Es of cancer immunoediting. Annu Rev Immunol 22: 329-360, 2004.

20. Marigo I, Dolcetti L, Serafini P, Zanovello P and Bronte V: Tumor-induced tolerance and immune suppression by myeloid derived suppressor cells. Immunol Rev 222: 162-179, 2008.

21. Gabrilovich DI and Nagaraj S: Myeloid-derived suppressor cells as regulators of the immune system. Nat Rev Immunol 9: 162-174, 2009.

22. Diaz-Montero M, Finke J and Montero AJ: Myeloid derived suppressor cells in cancer: Therapeutic, predictive, and prognostic implications. Semin Oncol 41: 174-184, 2014.

23. Zhao R, Li Q and Xiao B: Effect of Lycium barbarum polysaccharide on the improvement of insulin resistance in NIDDM rats. Yakugaku Zasshi 125: 981-988, 2005.

24. Li XM. Protective effect of Lycium barbarum polysaccharides on streptozotocin-induced oxidative stress in rats. Int J Biol Macromol 40: 461-465, 2007.

25. Chen Z, Kwong Huat Tan B and Chan SH: Activation of T lymphocytes by polysaccharide-protein complex from Lycium barbarum L. Int Immunopharmacol 8: 1663-1671, 2008.

26. GanL,HuaZhang S,Liang Yang Xand BiXuH:Immunomodulation and antitumor activity by a polysaccharide-protein complex from Lycium barbarum. Int Immunopharmacol 4: 563-569, 2004.

27. Chen Z, Lu J, Srinivasan N, Tan BK and Chan SH: Polysaccharide-protein complex from Lycium barbarum L. is a novel stimulus of dendritic cell immunogenicity. J Immunol 182: 3503-3509, 2009.

28. Miao Y, Xiao B, Jiang Z, Guo Y, Mao F, Zhao J, Huang X and Guo J: Growth inhibition and cell-cycle arrest of human gastric cancer cells by Lycium barbarum polysaccharide. Med Oncol 27: 785-790, 2010.

29. Zhang M, Chen H, Huang J, Li Z, Zhu C and Zhang S: Effect of Lycium barbarum polysaccharide on human hepatoma QGY7703 cells: Inhibition of proliferation and induction of apoptosis. Life Sci 76: 2115-2124, 2005

30. Booy S, van Eijck CH, Dogan F, van Koetsveld PM and Hofland LJ: Influence of type-I Interferon receptor expression level on the response to type-I Interferons in human pancreatic cancer cells. J Cell Mol Med 18: 492-502, 2014.

31. Shang D, Yang P, Liu Y, Song J, Zhang F and Tian Y: Interferon- $\alpha$ induces G1 cell-cycle arrest in renal cell carcinoma cells via activation of Jak-Stat signaling. Cancer Invest 29: 347-352, 2011

32. Mao F, Xiao B, Jiang Z, Zhao J, Huang X and Guo J: Anticancer effect of Lycium barbarum polysaccharides on colon cancer cells involves G0/G1 phase arrest. Med Oncol 28: 121-126, 2011.

33. Markowitz J, Luedke EA, Grignol VP, Hade EM, Paul BK, Mundy-Bosse BL, Brooks TR, Dao TV, Kondalasula SV, Lesinski GB, et al: A phase I trial of bortezomib and interferon-alpha-2b in metastatic melanoma. J Immunother 37: 55-62, 2014.

34. Zhu CP and Zhang SH: Lycium barbarum polysaccharide inhibits the proliferation of HeLa cells by inducing apoptosis. J Sci Food Agric 93: 149-156, 2013.

35. McIntosh GG, Anderson JJ, Milton I, Steward M, Parr AH, Thomas MD, Henry JA, Angus B, Lennard TW and Horne CH: Determination of the prognostic value of cyclin D1 overexpression in breast cancer. Oncogene 11: 885-891, 1995.

36. Chen H, Tang L, Peng X, Luo Z, Luo S and Tan W: Effects of IFN-alpha combined with IL-6 on cell growth and related genes expression and apoptosis of bone marrow cells from CGL patients. Zhonghua Xue Ye Xue Za Zhi 21: 341-344, 2000 (In Chinese). 
37. Zitzmann K, Brand S, De Toni EN, Baehs S, Göke B, Meinecke J, Spöttl G, Meyer HH and Auernhammer CJ: SOCS1 silencing enhances antitumor activity of type I IFNs by regulating apoptosis in neuroendocrine tumor cells. Cancer Res 67: 5025-5032, 2007.

38. Nakashima A, Kumakura S, Mishima S, Ishikura $H$ and Kobayashi S: IFN-alpha enhances TNF-alpha-induced apoptosis through down-regulation of c-Myc protein expression in HL-60 cells. J Exp Clin Cancer Res 24: 447-456, 2005.

39. He YL, Ying Y, Xu YL, Su JF, Luo H and Wang HF: Effects of Lycium barbarum polysaccharide on tumor microenvironment T-lymphocyte subsets and dendritic cells in H22-bearing mice. Chin Integr Med 3: 374-377, 2005 (In Chinese).

40. Luo Q, Li Z, Yan J, Zhu F, Xu RJ and Cai YZ: Lycium barbarum polysaccharides induce apoptosis in human prostate cancer cells and inhibits prostate cancer growth in a xenograft mouse model of human prostate cancer. J Med Food 12: 695-703, 2009.

41. Gan L, Wang J and Zhang S: Inhibition the growth of human leukemia cells by Lycium barbarum polysaccharide. J Hygiene Res 30: 333-335, 2001 (In Chinese).
42. Gómez-Benito M, Balsas P, Carvajal-Vergara X, Pandiella A, Anel A, Marzo I and Naval J: Mechanism of apoptosis induced by IFN-alpha in human myeloma cells: Role of Jak1 and Bim and potentiation by rapamycin. Cell Signal 19: 844-854, 2007.

43. Christiansson L, Söderlund S, Svensson E, Mustjoki S, Bengtsson M, Simonsson B, Olsson-Strömberg U and Loskog AS: Increased level of myeloid-derived suppressor cells, programmed death receptor ligand 1/programmed death receptor 1, and soluble CD25 in Sokal high risk chronic myeloid leukemia. PLoS One 8: e55818, 2013.

44. Zoglmeier C, Bauer H, Nörenberg D, Wedekind G, Bittner P, Sandholzer N, Rapp M, Anz D, Endres S and Bourquin C: CpG blocks immunosuppression by myeloid-derived suppressor cells in tumor-bearing mice. Clin Cancer Res 17: 1765-1775, 2011.

45. Zhu J, Zhao LH and Chen Z: Stimulation by Lycium bararum polysaccharides of the maturation of dendritic cells in murine bone marrow. Zhejiang da xue xue bao. Journal of Zhejiang University. Med Sci 35: 648-652, 2006 (In Chinese). 